\title{
Redes sociais virtuais: premissas teóricas ao estudo em ciência da informação
}

\author{
Virtual social networks: a theoretical approach \\ to the study in information science
}

Ruleandson do Carmo CRUZ

\section{RE S U M O}

Este artigo revisa trabalhos científicos de pesquisadores dedicados ao estudo das redes sociais - principalmente das redes sociais virtuais -, com enfoque em pontos relevantes ao campo da ciência da informação. Descreve teoricamente as redes sociais, as redes sociais virtuais, os sites de redes sociais virtuais e as comunidades virtuais. Conceitua os elementos de análise em redes sociais e em redes sociais virtuais. Caracteriza a informação circulante no contexto das redes sociais virtuais, bem como o usuário da informação online, o fluxo informacional e os elementos constituintes do capital social compartilhado em redes sociais formadas no ciberespaço. Apresenta constatações teóricas básicas ao estudo da informação em sites de redes sociais virtuais, dentre outros apontamentos.

Palavras-chave: Comunidade virtual. Informação. Redes sociais. Usuário.

\section{A B S T R A C T}

This article covers scientific works from researchers studying social networks - especially virtual social networks - with a focus on relevant topics of study of such features in the field of Information Science. It theoretically describes social networks, virtual social networks, its sites and virtual communities. The analytical elements in social networks and virtual social networks are conceptualized. The circulating information in virtual social network context is characterized, as well as online information users, the flow of information and the elements which form the social capital shared in cyberspace social networks. This paper also presents basic theoretic findings on the study of information in virtual social networks sites, among others considerations.

Keywords: Virtual community. Information. Social networks. Users.

\section{N T RO D U Ç Ã O}

Muito se tem falado, atualmente, sobre redes sociais. Com a popularização de sites como Orkut e Twitter, por exemplo, há quem chegue a classificá-los como redes sociais, embora não o sejam. Sites como esses são apenas espaços virtuais para a formação e exibição de redes sociais virtuais. $\bigcirc$ que os diferencia dos demais é que eles são voltados à formação de redes sociais virtuais, no entanto é o uso do site que propicia a existência de tais redes e a interação entre os usuários, e não o site em si.

Os sites de redes sociais são a ferramenta online mais acessada pelos usuários da Internet em todo o mundo (Kebede, 2009), tornando importante seu estudo.

\footnotetext{
1 Mestrando, Universidade Federal de Minas Gerais, Escola de Ciência da Informação, Programa de Pós-Graduação em Ciência da Informação. Av. Antônio Carlos, 6627, Campus Universitário, 30161-970, Belo Horizonte, MG, Brasil. E-mail: <ruleandson@gmail.com>. Recebido em 14/1 1/2009 e aceito para publicação em 2/12/2010.
} 
Enquanto as estimativas indicam que dois terços da população online global participam de tais sites, no Brasil, o uso dos sites voltados à formação de redes sociais virtuais é ainda mais intenso: aproximadamente 90\% dos usuários brasileiros da Internet estão nessas redes e gastam nelas $23 \%$ do seu tempo online (Schnoor, 2008). Portanto, estudar a informação circulante em sites voltados à formação de redes sociais virtuais é tarefa não só necessária à Ciência da Informação (Cl) como também missão complexa, que exige algumas premissas teóricas básicas. Apresentar tais premissas é o objetivo da presente revisão teórica².

\section{REDES SOCIAIS VIRTUAIS}

Segundo Marteleto e Tomaél (2005, p.81), a Análise de Redes Sociais (ARS) é "uma metodologia oriunda da Antropologia Cultural e da Sociologia, mas com aplicações em diversas disciplinas, cujo foco analítico recai sobre as relações e interações entre os indivíduos, como maneira de entender a estrutura relacional da sociedade".

De acordo com as autoras, dentre os vários tipos de estudos de redes sociais existentes, há pesquisas que priorizam dois objetivos da ARS oriundos da antropologia da informação: 1) entender o que são e como funcionam as estruturas e as relações sociais e de que maneira os sujeitos em interação concorrem para sua reprodução e transformação; 2) mapear as diferentes configurações comunicacionais e informacionais da rede social para perceber as mediações utilizadas para a construção do conhecimento social, o conhecimento em estado prático. Para as autoras, esses estudos costumam fundamentar perguntas relativas aos conceitos de conhecimento, comunicação e informação, principalmente, no campo da $\mathrm{Cl}$.

Segundo Capurro (2003), esta é uma das definições clássicas da Cl: ciência que tem como objeto "a produção, seleção, organização, interpretação, armazenamento, recuperação, disseminação, transformação e uso da informação" (Griffith, 1980). Assim, para
Capurro (2003), a Cl "nasce em meados do século XX com um paradigma físico, questionado por um enfoque cognitivo idealista e individualista, sendo esse por sua vez substituído por um paradigma pragmático e social". Acerca de tais paradigmas do campo da $\mathrm{Cl}$, o autor sintetiza-os da seguinte maneira: a) paradigma físico postula que há um objeto físico transmitido por um emissor a um receptor, com foco na recuperação da informação; b) paradigma cognitivo (idealista e individualista) - entende a informação como sendo objetiva e relacionada aos conteúdos intelectuais existentes somente em espaços cognitivos ou mentais; c) paradigma social - compreende a informação em contextos sociais e materiais humanos, com foco na interação entre os usuários da informação.

Nesse contexto de paradigma social da $\mathrm{Cl}$, Marteleto e Tomaél (2005) observam que as pesquisas em antropologia da informação, por meio dos pressupostos anteriormente apresentados, fundamentam $o$ alcance da metodologia de ARS no entendimento do conhecimento, da comunicação e da informação como fenômenos sociais.

Desse modo, a partir do entendimento de que as redes sociais são um espaço para compartilhamento de informações, é preciso conceituar informação. Capurro (2003) assegura que definir informação é uma das tarefas mais complexas e amplas da $\mathrm{Cl}$. Assim, para efeitos deste estudo, adota-se o seguinte entendimento de informação:

Informação não é o produto final de um processo de representação, nem algo transportado de uma mente a outra, ou, enfim, algo a ser retirado do casulo de uma subjetividade, mas uma dimensão existencial de nosso ser no mundo junto com os outros [...]. A informação é, mais precisamente, a articulação de uma compreensão pragmática de um mundo comum compartilhado. Esta compreensão a priori permanece em grande medida tácita ainda quando a articulamos em forma falada ou escrita, dado que, por nossa finitude, nunca podemos explicitá-la totalmente (Capurro, 1992, online, tradução nossa).

\footnotetext{
2 Diante do crescente aumento na quantidade de publicações sobre redes sociais, Otte e Rousseau (2002) comprovam um aumento linear entre 1974 e 2000 e um número 20 vezes maior no número de artigos sobre redes encontrados em bases de dados como Sociological Abstracts Database, MedLine Advanced e PsycINFO entre 1981 e 1999 -, recorre-se a revisões de literatura realizadas por pesquisadores que são referências no campo de comunicação e informação e que se dedicaram por anos à leitura de textos sobre redes sociais. Diante das limitações temporais, fazem-se, quando necessário, citações de citações, indicando-se em nota de rodapé as obras originais consultadas pelos autores aqui citados.
} 
Nesse sentido, analisar o compartilhamento e a relação do usuário com a informação não é tarefa somente da ARS, mas também dos estudos de usuários definidos como "uma investigação que objetiva identificar e caracterizar os interesses, as necessidades e os hábitos de uso de informação de usuários reais e/ou potenciais de um sistema de informação" (Dias; Pires, 2004, p. 11 ). De acordo com Wilson (1999), tais estudos foram iniciados na década de 1940 com as pesquisas de busca e de uso das informações disponibilizadas em bibliotecas, sendo tais pesquisas voltadas, no início, principalmente à comunidade científica.

Segundo Figueiredo (1994), somente na década de 1970 os estudos de usuários - antes focados em cientistas das ciências puras e engenheiros (anos 1940), depois nos tecnologistas e educadores (anos 1960) passam a considerar os cientistas sociais de modo geral e altos escalões da administração governamental.

Segundo Gonzáles de Gomez, na década de 1980, principalmente nos países de terceiro mundo, o campo da $\mathrm{Cl}$ começa a preocupar-se com a democratização da informação (Araújo 2008, p.8). Esse movimento é concretizado por meio da constituição da subárea informação social (Cardoso, 1994). Para Lallement (2004, p.9), esta subárea "toma como pressuposto teórico básico a ideia de tensionalidade, da existência de conflitos no âmbito da realidade humana e social, em oposição à de integração, basilar das abordagens positivistas e funcionalistas das ciências humanas e sociais". Essa nova abordagem busca estudar outros usuários da informação, ampliando o foco das pesquisas - antes direcionado, principalmente, ao usuário acadêmico, científico e/ou organizacional - aos usuários não especializados, por vezes marginalizados pelos estudos científicos (Araújo, 2008).

Figueiredo (1994) apresenta uma divisão comum na literatura de $\mathrm{Cl}$ em relação aos estudos de usuários, dividindo-os em estudos orientados ao sistema (biblioteca ou serviço de informação) e estudos voltados ao usuário, que investigam o comportamento de uma comunidade na obtenção de informação.

Outra divisão de tais estudos refere-se à abordagem tradicional e à alternativa. A abordagem tradicional, segundo Ferreira (1996), trata a informação como externa, objetiva, algo fora do indivíduo. Desse modo, a informação existiria em um mundo ordenado e poderia ser descoberta, definida e medida. $\bigcirc$ usuário, nessa abordagem, é passivo em relação à informação: ele a recebe, mas sua ação sobre essa informação não é considerada. A abordagem alternativa, segundo o mesmo autor, caracteriza-se por: a) observar o ser humano como ser construtivo e ativo; b) considerar o indivíduo como orientado de acordo com a situação; c) visualizar holisticamente as experiências do indivíduo; d) focalizar os aspectos cognitivos envolvidos; e) analisar sistematicamente a individualidade das pessoas; f) empregar maior orientação qualitativa (Ferreira, 1996). Ferreira (1996, online) cita que os usuários da informação, na abordagem alternativa, são entendidos como:

Pessoas com necessidades cognitivas, afetivas e fisiológicas fundamentais próprias que operam dentro de esquemas que são partes de um ambiente com restrições socioculturais, políticas e econômicas. Essas necessidades próprias, os esquemas e o ambiente formam a base do contexto do comportamento de busca de informação. Os mais importantes atos de comunicação - questionar, planejar, interpretar, criar, resolver, responder, tão esquecidos no modelo tradicional - são amplamente valorizados no modelo alternativo.

Segundo Rabello (1980), para entender os usuários da informação, é preciso que a $\mathrm{Cl}$ busque aporte teórico em outras ciências. Sob essa mesma ótica interdisciplinar, Marteleto e Tomaél (2005, p.82) afirmam que, apesar das especificidades da metodologia de ARS no campo da $\mathrm{Cl}$, tal análise não possui arcabouço teórico próprio, sendo necessário ao pesquisador combinar teorias apropriadas ao ambiente e às questões em estudo.

Feitas as ressalvas ao pesquisador da informação em redes sociais, apresentam-se a seguir conceituações teóricas básicas ao entendimento da informação circulante em sites voltados à formação de redes sociais virtuais.

\section{Redes sociais}

A Internet é a espinha dorsal da Comunicação Mediada pelo Computador (CMC), pois liga a maior parte das redes. Apesar das desigualdades e de fatores como a exclusão digital, a Internet é hoje o meio de comunicação interativo universal via computador da Era da Informação (Castells, 2002). 
No entanto, rede social não é realidade exclusiva da Internet. Bem antes da teia mundial de computadores agrupar pessoas com interesses comuns e da existência de sites como o Orkut, redes sociais já se faziam presentes. A definição de redes e de comunidades é sempre discutida, por exemplo, pela sociologia clássica e contemporânea (Recuero, 2001). A ideia de redes sociais também está presente nas conhecidas vias de comunicação informais dos cientistas - os chamados colégios invisíveis -, discutidos desde a década de 1960 (Moreira, 2005).

De acordo com Recuero (2004), o termo rede como modo de se compreender uma estrutura social é utilizado pela primeira vez pelo matemático Ëuler, por volta do século XVIII, quando ele tenta relatar um modo de atravessar todas as setes pontes da cidade prussiana de Königsberg sem passar duas vezes pela mesma ponte. A impossibilidade de tal travessia sem repetição ser realizada é comprovada por Ëuler por um teorema no qual as pontes são arestas e os lugares a serem conectados são nós.

Esclarece que tal teorema origina a teoria dos grafos - sendo os grafos, nesse contexto, a representação de um conjunto de nós conectados por arestas, formando uma rede -, uma das bases dos estudos das redes sociais na sociologia, com forte ancoramento na Análise Estrutural, iniciada nas décadas de 1960 e 1970, cujo objetivo é o estudo das estruturas sociais por meio de uma abordagem sistêmica, por vezes referenciada como analítico-cartesiana, que busca compreender o todo por meio do estudo das partes, e que a partir do século XX começa a estudar o todo por meio da análise da interação entre as partes de uma estrutura social (Recuero, 2009b, p. 17).

Nesse sentido, segundo Alcará et al. (2005, p.93), "a própria natureza humana nos liga a outras pessoas e estrutura a sociedade em rede". Nessa estruturação, "os nós da rede representam cada indivíduo, e suas conexões, os laços sociais que compõem os grupos" (Recuero, 2009a, p.25). Assim, Castells (2002, p.566) define rede social como:

[...] um conjunto de nós interconectados. Nó é o ponto no qual uma curva se entrecorta. Concretamente, o que um nó é depende do tipo de redes concretas de que falamos. [...] Redes são desde que compartilhem os mesmos códigos de comunicação.

Marteleto (2001, p.72), por sua vez, define rede social como o "conjunto de participantes autônomos, unindo ideias e recursos em torno de valores e interesses compartilhados", e Recuero (2009b, p.24) a caracteriza como:

Um conjunto de dois elementos: atores (pessoas, instituições ou grupos; os nós da rede) e suas conexões (interações ou laços sociais) [...] Uma rede, assim, é uma metáfora para observar os padrões de conexão de um grupo social, a partir das conexões estabelecidas entre os diversos atores. A abordagem da rede tem, assim, seu foco na estrutura social, onde não é possível isolar os atores sociais e nem suas conexões.

Desse modo, o interesse partilhado pelos atores da rede social é o capital social, definido como "normas, valores, instituições e relacionamentos compartilhados que permitem a cooperação dentro ou entre os diferentes grupos sociais" (Marteleto; Oliveira e Silva, 2004, p.44).

\section{Elementos, análise e tipos de redes sociais}

Sobre os elementos das redes socias, Marteleto e Tomaél (2005, p.86), salientam que:

O elemento fundante das redes sociais são as
relações de convívio, interação e pertencimento,
nas quais se identificam a sua força e razão de
ser. O nível lingüístico permite apreender dos
recursos inviduais e coletivos extraídos dos acer-
vos cognitivos e informacionais dos atores em
situações de interação. Por último ressaltam-se
os elementos mais próximos de uma ação de
clareamento e intervenção na realidade pelos
atores em interação.

Por sua vez, ao descreverem os conceitos fundamentais na análise de redes sociais, Wasserman e Faust (1994, p.17) apontam e descrevem: ator; laço relacional; díade; tríade; subgrupo; grupo; e relação. Assim, situando sinteticamente tais conceitos, diz-se que, na rede: ator é um distinto indivíduo, corporação ou unidade social coletiva; laço relacional é o que estabelece a ligação entre um par de atores, sendo os mais comuns tipos de laços os de avaliação de uma pessoa por outra - como laço de amizade ou respeito, transferência de materiais ou recursos, associação ou afi- 
liação - como o laço entre atores de um evento ou clube social, comportamento de interação - como laços de conversação ou envio de mensagens, conexão física, relações formais - como autoridade, e relações biológicas; díade consiste em um par de atores e no possível laço entre eles, assim, ela analisa se os laços são recíprocos ou se ocorrem laços de múltiplas relações entre os atores; tríade é o grupo de três atores e os possíveis laços entre eles; subgrupo é um subconjunto de atores dentro da rede e todos os laços entre eles; grupo é um conjunto finito de atores que conceitual e teoricamente, ou por razões empíricas, são definidos como finitos em determinada avaliação da rede; e relação é a coleção de laços de um específico tipo entre membros de um grupo.

Colonomos (1995), ressalta que a rede social é caracterizada pelos múltiplos elos qualitativos e quantitativos entre os diferentes atores, e que, apesar de compreender também as relações de poder e dependência, ela segue uma lógica associativa, desdobrando-se na horizontalidade das relações sociais, sendo essa a especificidade do seu funcionamento.

Nessa perspectiva, as duas unidades de análise de redes sociais destacadas por Marteleto e Tomaél (2005) são: relações e ligações. Para as autoras, as relações (relations), por vezes denominadas fios (strands), são determinadas de acordo com seu conteúdo, direção e intensidade e referem-se aos recursos de informação trocados na rede. A relação pode ser direta - um ator relacionando-se diretamente com o outro - ou indireta - um ator relacionando-se com um terceiro por intermédio de um segundo ator ao qual ele se liga diretamente. Além disso, pode-se também avaliar a relação de acordo com a intensidade, verificando-se, por exemplo, se há grande ou pequena troca de capital social, pequena ou grande frequência de contato, ou, ainda, compartilhamento de informações importantes ou triviais (Garton et al., 1997, online).

A segunda unidade de análise são as ligações (tie), conhecidas como laços ou vínculos, definidas como aquilo que conecta um par de atores por uma ou mais relações, podendo os pares conectar-se devido a uma relação ou a múltiplas relações identificadas quando ocorrem várias relações em uma mesma ligação (Wellman, 1992b).

A partir da tradicional divisão em laço fraco e laço forte (weak ties; strong ties), Marteleto e Tomaél (2005) definem ligações fracas como as que se referem a atores envolvidos em menor grau e que provocam a baixa densidade da rede, existente quando muitas das possibilidades de relacionamento estão ausentes - e ligações fortes como as que se referem a atores com envolvimento maior e que resultam em uma rede densamente ligada, com muitas possibilidades de ligações presentes (Granovetter, 1982).

As autoras citam ainda outras duas tipificações das relações em uma rede social: ligações simétricas, quando a forma ou o conteúdo é igual em todas as ligações entre os atores, como no caso de atores que trabalham em uma mesma organização, e ligações assimétricas, quando a forma ou o conteúdo são diferentes na ligação entre atores, no caso em que, por exemplo, um ator fornece informações a outro, mas esse outro não lhe fornece informações (Marteleto; Tomaél, 2005).

Frisando ser a rede social composta por um conjunto de ligações e ser o exame dos padrões dessas relações capaz de descrever a rede social, Marteleto e Tomaél (2005) dizem haver duas principais formas de análise das redes sociais: rede egocêntrica e rede total ou completa. Ao definir a rede egocêntrica (Ego Centered Network), as autoras recorrem ao pensamento de diversos autores para afirmar ser ela uma rede pessoal, em que as relações são avaliadas a partir de um ator central, sendo os demais atores considerados com base nas relações mantidas com tal ator (Emirbayer; Goodwin, 1994; Garton et al., 1997). Em contraponto, a rede total ou completa (While Network) considera a ocorrência ou não ocorrência de relações entre todos os atores da rede, apresentando assim as ligações que todos os atores mantêm entre si (Marteleto; Tomaél, 2005).

Ao analisar as propriedades da rede - o modo como os atores conectam-se - Marteleto e Tomaél (2005) descrevem as mais recorrentes medidas ou indicadores usados para facilitar a análise e o entendimento da rede social: coesão social; densidade da rede; transitividade; distância geodésica; fluxo máximo; centro e periferia. As autoras definem as propriedades das redes sociais, como coesão social (social cohesion), a presença de ligações fortes entre os atores, pressupondo uma rede densa; densidade da rede (network density), que mensura a quantidade de ligações em uma rede quanto maior o número de ligações maior será a densidade da rede; transitividade (transitivity), que "mede o grau de flexibilidade e cooperação de uma rede" (Fazito, 2002), permitindo visualizar o fluxo de informa- 
ções entre três atores que não estejam ligados reciprocamente; distância geodésica (geodesic distance), menor distância entre dois pontos, refere-se ao número de ligações entre dois atores na rede (Hanneman, 2001); fluxo máximo (maximum flow), real conexão entre dois atores, por levantar possíveis caminhos de distribuição entre atores, identificando pontos de estrangulamento, caminhos em que a informação não alcança um ator em específico (Hanneman, 2001); e centro e periferia (center/periphery), em que o centro é um grupo coeso de atores, conectados com alta densidade, e a periferia são os atores pouco conectados entre si e ligados mais ao centro da rede (Borgatti; Everett, 1999).

Compreendendo os grupos como estruturas relacionais descobertas empiricamente na análise da rede social, Marteleto e Tomaél (2005) revisam a literatura sobre análise de redes sociais para descrever os principais grupos encontrados nas redes sociais: díade interação entre dois atores, somente analisável se comparada ao conjunto de outras díades; clique - conjunto de atores mais estreitamente relacionáveis entre si do que com o restante da rede; círculo social ou círculo egocêntrico - grupo em que os atores ligam-se direta e fortemente à maioria, semelhante ao clique; cluster - conjunto de relações similares que resulta em área altamente densa da rede, semelhante ao clique (Barnes, 1972; Emirbayer; Goodwin, 1994; Lopes, 1996; Garton et al., 1997; Hanneman, 2001 ; Marteleto, 2001; Scott, 2001).

Além da divisão da rede social em grupos, Marteleto e Tomaél (2005, p.93) ressaltam que analistas costumam dividi-la também de acordo com as similaridades do conjunto de ligações: análise posicional (position analysis), que verifica algumas posições centrais na rede com maior acesso às fontes de informações e outras com acesso limitado. As autoras salientam que a medida de centralidade (centrality) é ferramenta bastante usual para identificar atores-chave na rede, portanto um ator é central em uma rede quando pode comunicar-se diretamente com vários outros atores ou está próximo a eles, ou ainda se outros atores o usarem como intermediário em suas comunicações (Gomés et al., 2003).

Portanto, na rede social, as posições de centralidade podem ser das seguintes ordens: centralidade de grau (degree centrality) - posicionamento de um ator em relação às trocas e comunicações da rede; centralidade da informação (information centrality) - ator que recebe informações vindas da maior parte da rede; centralidade de proximidade (closeness centrality) - proximidade de um ator em relação a outras ligações da rede, analisa a independência de um ator em relação ao controle de outros (Barnes, 1972; Emirbayer; Goodwin, 1994; Lopes, 1996, Garton, 1997; Marteleto, 2001).

\section{Fluxo de informações e comportamento informacional em redes sociais}

Acerca do papel da informação na rede social, Tomaél et al. (2005, p.93) afirmam que "a inserção em rede é determinante para o compartilhamento da informação e do conhecimento, uma vez que as redes são espaços valorizados para o compartilhamento da informação e para a construção do conhecimento". As autoras observam ainda que a ideia de rede remete à ideia primitiva de caça, com isso, "por transposição, a rede é assim um instrumento de captura de informações" (Franchinelli et al., 2004). As autoras observam que as redes sociais são responsáveis por:

\begin{abstract}
Manterem canais e fluxos de informação em que a confiança e o respeito entre atores os aproximam e os levam ao compartilhamento de informações que incide no conhecimento detido por eles, modificando-o ou ampliando-o [...].

Favorecem, igualmente, ligações entre atores com o poder de direcionar os fluxos de informação a indivíduos que partilham de interesses comuns (Tomaél et al., 2005, p. 102).
\end{abstract}

A informação, é o que mobiliza as redes sociais, tornando-as vetor estratégico importante e contumaz, visto que a necessidade de informação é natural ao ser humano e às organizações, e as redes sociais são o caminho natural para a busca de informações (Tomaél et al., 2005, p. 102). Essa visão é compartilhada por Araújo (2001, online), para quem "as práticas informacionais, por sua vez, estruturam as redes sociais, pois são, em última instância, conjuntos de múltiplas relações de associações coletivas", e por Floriani (2007), que observa serem as redes sociais um instrumento "que conecta indivíduos e permite o intercâmbio de informações no fluxo" (Floriani, 2007, p.77). Também sob essa ótica, Silva (2004, p.5) ressalta que "as redes são animadas por fluxos. São dinâmicas e ativas, mas não trazem em si mesmas seu princípio dinâmico, que é um movimento do social". 
De acordo com Morigi et al. (2006), o conceito de fluxo da informação, anteriormente citado, tem sua origem ligada ao fluxograma - advindo dos estudos administrativos -, que tem a função de sintetizar de modo sistêmico rotinas, procedimentos e processos com o objetivo de esquematizar a informação para analisar a situação existente e realizar melhorias, se necessário. Para os autores, no contexto informacional, o fluxo carrega a ideia de "representar os tráfegos, os circuitos comunicacionais, isto é, o modo como fluem as mensagens, sejam elas orais, audiovisuais ou escritas. Como ocorre essa sequência contínua da troca de informações entre os sujeitos emissores e receptores" (Morigi et al., 2006, p. 198). Barreto (1998, p.122) compreende o fluxo informacional como "uma sucessão de eventos, de um processo de mediação, entre a geração da informação por uma fonte emissora e a aceitação da informação pela entidade receptora", sendo, assim, o que liga gerador e receptor da informação. Sobre o fluxo, Dias (2006, p. 148) é categórico ao afirmar que "os fluxos, de todo tipo - das mercadorias às informações - pressupõem a existência de redes".

Nesse sentido, analisar fluxos de informação em sites de redes sociais, como esta pesquisa se propõe, exige um estudo do comportamento e da cultura informacional dos usuários da informação nas comunidades virtuais em análise. Comportamento informacional "se refere ao modo como os indivíduos lidam com a informação. Inclui a busca, o uso, a alteração, a troca, o acúmulo e até mesmo $o$ ato de ignorar os informes [...] envolve atos individuais" (Davenport, 2000, p. 110 ), e cultura informacional "abrange grupos ou organizações - em particular os valores e crenças de um grupo [...]. Por cultura em relação à informação, entendo o padrão de comportamentos e atitudes que expressam a orientação informacional" (Davenport, 2000, p.110).

Apesar de Davenport (2000) não tecer outras considerações sobre o comportamento e a cultura informacional, entende-se que a definição do autor, que diferencia os dois conceitos, objetiva descrever quais atos individuais ou do grupo devam ser observados ao avaliar-se tanto o comportamento quanto a cultura informacional, visto que demais descrições caberão ao pesquisador de determinado usuário e/ou grupo de usuários e serão dependentes das práticas informacionais de tais usuários.

Apresentadas as principais definições de rede social e de seus elementos e unidades de análise, faz- -se necessária a diferenciação entre rede social em sentido amplo e rede social virtual, pois, conforme Recuero (2009d, online), "as redes sociais na Internet não deveriam ser vistas como um reflexo completo das redes sociais offline, mas como desveladoras de vários de seus aspectos e como complexificadoras de seu espaço de atuação".

\section{Redes sociais virtuais}

Garton et al. (1997) dizem que "uma rede social forma-se quando um computador conecta pessoas ou organizações" (tradução do autor). Assim, Tomaél et al. $(2005$, p.95) observam que:

As redes sociais ultrapassaram o âmbito acadêmico/científico, conquistando e ganhando espaço em outras esferas. E podemos observar esse movimento chegando à Internet e conquistando cada vez mais adeptos, aglutinando pessoas com objetivos específicos, ou apenas pelo prazer de trazer à tona ou desenvolver uma rede de relacionamentos.

Transpondo a metáfora de rede, usada para entender uma estrutura social, para o ambiente online, Recuero (2009a, p.25) define rede social virtual como a "teia de conexões que espalham informações, dão voz às pessoas, constroem valores diferentes e dão acesso a esse tipo de valor [capital social]".

Para Tomaél et al. (2005, p.95), a existência de redes sociais na Internet é possibilitada pela existência de um:

Software social [grifo nosso] que, com uma interface amigável, integra recursos além dos da tecnologia da informação. $\bigcirc$ uso desses recursos gera uma rede em que os membros convidam seus amigos, conhecidos, sócios, clientes, fornecedores e outras pessoas de seus contatos para participar de sua rede, desenvolvendo uma rede de contatos profissional e pessoal, que certamente terá pontos de contatos com outras redes. Enfim, são ambientes que possibilitam a formação de grupos de interesses que interagem por meio de relacionamentos comuns.

O referido software social, segundo Recuero (2004, p.7), são "sistemas que visam proporcionar conexões entre as pessoas, gerando novos grupos e comunidades, simulando uma organização social". 


\section{Elementos das redes sociais virtuais}

Recuero (2009b) divide os elementos das redes sociais virtuais em atores e conexões. Assim, a autora diz que em qualquer rede social os atores, representados na rede pelos nós, são as pessoas envolvidas na rede analisada. Tais atores formam e moldam as estruturas sociais por meio da interação e constituição de laços sociais. Essas características não diferem muito o ator da rede social virtual do ator da rede social offline, sendo a principal característica do ator da rede social virtual o fato de ele ser uma representação do ator social, uma construção identitária na Internet.

Um ator, assim, pode ser representado por um weblog, por um fotolog, por um twitter ou mesmo por um perfil no Orkut. E, mesmo assim, essas ferramentas podem apresentar um único nó (como um weblog, por exemplo), que é mantido por vários atores (um grupo de autores do mesmo blog coletivo) [...]. São espaços de interação, lugares de fala, construídos pelos atores de forma a expressar elementos de sua personalidade ou individualidade (Recuero, 2009b, p.25).

Desse modo, Doring (2002), Sibilia (2008), Lemos (2002), Recuero (2001) e Recuero (2009b), observam que a construção e a expressão da identidade no ciberespaço pelo ator da rede social virtual é um processo permanente que inclui a apropriação de perfis em sites como o Orkut e o MySpace. Tais apropriações são "a presença do 'eu' no ciberespaço, um espaço privado e, ao mesmo tempo, público. Essa individualização da expressão de alguém 'que fala' por meio desse espaço é que permite que as redes sociais sejam expressas na Internet" (Recuero, 2009b, p.27).

Acerca dessa construção identitária no ciberespaço, Sibilia (2008), citado por Recuero (2009b, p.27), diz que a necessidade de exposição pessoal, característica marcante de nossa sociedade, é o imperativo da visibilidade, resultante da interseção entre público e privado e da globalização, responsável por exacerbar o individualismo. Nesse sentido, Efimova (2005, online), diz que "é preciso ser 'visto' para existir no ciberespaço. É preciso constituir-se parte dessa sociedade em rede, apropriando-se do ciberespaço e construindo um 'eu' ali", sendo necessário compreender como os atores constroem os espaços de expressão desse "eu" para entender como se estabelecem as conexões nas redes sociais virtuais.
Sobre tais conexões, promovidas pela interação entre os atores, Donath (1999), diz que a percepção do outro é fundamental para a interação humana, o que é complexificado pelo ciberespaço, no qual não há comunicação presencial (física), levando os atores a serem percebidos por suas palavras e expressões como fotos e informações promovedoras de individualidade e de simpatia em relação a seu ator, construindo as percepções dos atores acerca de outro ator social e proporcionando pistas à interação social entre eles. Assim, os perfis criados por indivíduos e que os representam como atores no ciberespaço são "pistas de um 'eu' que poderá ser percebido pelos demais. São construções plurais de um sujeito, representando múltiplas facetas de sua identidade" (Recuero, 2009b, p.30).

Dentre as possibilidades de construção identitária nos sites de redes sociais, há perfis que fingem ser o de algum outro ator social (celebridades ou pessoas comuns), conhecidos como perfis fakes (falsos). Dal Bello (2008, online) sintetiza tais perfis da seguinte maneira:

[o perfil fake] constitui uma forma de resistência ao potencial de indexação e identificação da plataforma: os fake possibilitam que o sujeito-usuário espione e se manifeste sem revelar sua identidade. Assim, ora revestem o anonimato de bom humor, ironia ou sarcasmo; ora constituem verdadeiros fantasmas sem rosto que assombram os demais, praticando uma espécie de covarde terrorismo virtual: 'Eu sei quem é você, mas você não sabe quem sou eu'.

O segundo elemento constituinte das redes sociais virtuais, para Recuero (2009b), são as conexões, os laços sociais formados por meio da interação social entre os atores, cujas variações alteram as estruturas da rede, e que somente são percebidos por meio dos rastros que um ator deixa no ciberespaço, como, por exemplo, comentários em um blog.

A autora caracteriza a interação no ciberespaço como sendo totalmente mediada pelo computador e por isso mesmo influenciada, ou limitada, pelas possibilidades de comunicação das ferramentas utilizadas pelos atores. Tal interação é dividida por Reid (1991), em síncrona e assíncrona. A interação síncrona ocorre quando se simula uma interação em tempo real, com expectativa de resposta imediata e com os atores presentes no mesmo momento temporal, como nos chats. 
A assíncrona efetua-se quando a expectativa de resposta à mensagem não é imediata, pois se espera que o ator responda, posteriormente, como ocorre nos e-mails e fóruns.

Primo (2003, p.61), classifica as interações virtuais em mútua ou reativa. A interação mútua é marcada por relações interdependentes e processos de negociação nos quais os atores envolvidos afetam-se mutuamente, como os comentários em blogs que propiciam diálogos com o autor do blog e entre os comentaristas. Com outras características, a interação reativa limita-se a relações determinísticas de estímulo e resposta, como a de um ator com um hiperlink, na qual ele pode apenas decidir se clica ou não em tal link, mas não pode alterá-lo.

Desse modo, Recuero (2009b) aponta ainda a migração, possibilidade da interação entre os atores espalhar-se por diversas plataformas online, como blogs, Orkut, fotolog, entre outros, como outro fator marcante da interação no contexto da CMC e que auxilia na percepção da multiplexidade das relações.

Assim "a interação no ciberespaço também pode ser compreendida como uma forma de conectar pares de atores e de demonstrar que tipo de relação esses atores possuem. Ela pode ser diretamente relacionada aos laços sociais" (Recuero, 2009b, p.34). Para a autora, em conjunto, tais interações formam as relações sociais, definidas pelos padrões de interação entre os atores da rede social virtual.

Garton et al. (1997) afirmam que, nas redes, as relações sociais ajudam a construir os laços sociais, criados a partir das interações entre os atores. Tendo várias classificações na discussão das redes sociais, os laços sociais são contextualizados por Recuero (2009b) no ambiente virtual e divididos em laços associativos e laços dialógicos. Para a autora, os laços associativos são gerados pela interação reativa, como o ato de aceitar o perfil de alguém em sua rede, trocar links etc., enquanto os laços dialógicos são formados pela interação mútua, como conversar com alguém por meio de determinada rede social virtual. Assim, Recuero (2009b) destaca também o pertencimento relacional, advindo da interação mútua e do sentimento de pertencimento à rede decorrente do elemento relacional e dialógico, e o pertencimento associativo, decorrente da interação reativa e do sentimento de pertencimento à rede ligado à associação e gerado por essa ação formal, pois o ator participa da rede, mas não interage mutuamente com os demais atores.

Acerca da natureza dos laços sociais nas redes sociais virtuais, a autora rememora a discussão anteriormente apresentada sobre laços fortes e fracos, compreendendo-os de modo semelhante e acrescentando que a Internet suporta laços altamente especializados, formados por relações de mesmo tipo, e laços multiplexos, formados por grupos que utilizam vários sistemas para interagir.

Com a interação estabelecida e os laços formados, os atores das redes sociais virtuais podem compartilhar o capital social. No estudo das redes sociais na Internet, Recuero (2009b, p.50) observa que:

O conceito de capital social [grifo nosso], entretanto, é variado e não há uma concordância, entre os estudiosos, sobre qual vertente deve ser seguida (p.44) ' [...] consideramos o capital social como um conjunto de recursos de um determinado grupo' (recursos variados e dependentes de sua função, como confirma Coleman, 1988) 'que pode ser usufruído por todos os membros do grupo, ainda que individualmente, e que está baseado na reciprocidade' (de acordo com Putnam, 2000). 'Ele está embutido nas relações sociais' (como explica Bourdieu, 1983) 'e é determinado pelo conteúdo delas' (Gyarmati; Kyte, 2004; Bertolini; Bravo, 2001). 'Portanto, para que se estude o capital social dessas redes, é preciso estudar não apenas suas relações, mas, igualmente, o conteúdo das mensagens que são trocadas através delas'. Esta ideia, baseada principalmente no conceito de Coleman (1988), mas com algumas ressalvas associadas a outros autores, parece ser a mais indicada para o estudo do capital social nas redes sociais. Isso porque ela trabalha o caráter estrutural do capital social, sua capacidade de transformação de acordo com a função e sua base na reciprocidade, que consideramos os elementos essenciais do conceito.

Assim, Recuero (2009b) apresenta uma categorização do capital social, para que ele seja visualizado nas redes sociais, de acordo com a classificação construída por Bertolini e Bravo (2001), baseada na definição de Coleman (1988), que compreende as categorias de capital social como os recursos aos quais os atores têm acesso por meio da rede (Recuero, 2009b, p.50). As categorias definem os tipos de capital social como: 
a) relacional - que compreenderia a soma das relações, laços e trocas que conectam os indivíduos de uma determinada rede; b) normativo que compreenderia as normas de comportamento de um determinado grupo e seus valores; c) cognitivo - que compreenderia a soma do conhecimento e das informações colocadas em comum por determinado grupo; d) confiança no ambiente social - que compreenderia a confiança no comportamento de indivíduos em um determinado ambiente; e) institucional - que incluiria as instituições formais e informais que se constituem na estruturação geral dos grupos, onde é possível conhecer as 'regras' da interação social, e onde o nível de cooperação e coordenação é bastante alto (grifos do autor).

Definidas as categorias de capital social, Recuero (2009b) recorre aos mesmos autores para dizer que os aspectos do capital social dividem-se em aspectos individuais (atores como primeiro nível de capital social) - aqueles que variam de acordo com os atores: capital social relacional, normativo, e cognitivo; e aspectos do grupo (segundo nível de capital social) - aqueles que somente podem ser utilizados pela coletividade: confiança no ambiente social e institucional. A autora frisa que tais aspectos podem coexistir.

Em seguida, Recuero (2009b) apresenta conceitos com entendimentos semelhantes aos anteriormente apresentados neste trabalho - e que, portanto, não serão reapresentados -, sendo eles elementos de análise (rede total e rede egocentrada) e propriedades da rede (conexão, densidade, centralidade, centralização e multiplexidade).

\section{Estruturas das redes sociais virtuais}

Redes são metáforas estruturais utilizadas para compreender os agrupamentos sociais por meio de sua estrutura, assim as redes sociais virtuais possuem estruturas (topologias) construídas através dos laços sociais que unem os atores (Recuero, 2009b). Desse modo, a autora, valendo-se do pensamento de vários autores, compreende as topologias das redes sociais na Internet como de três tipos: rede igualitária, rede mundos pequenos e rede sem escalas.

A rede igualitária é definida como uma rede na harmônica e sem conglomerados, por haver melhor distribuição das conexões entre nós. A rede mundos pequenos dá-se ao considerar as redes sociais como interdependentes e por isso os atores estariam ligados em algum nível; em larga escala, as conexões mostrariam poucos graus de separação entre as pessoas em todo o planeta. Por sua vez, a rede sem escalas consiste na premissa de que as redes têm poucos nós altamente conectados (hubs ou conectores) e a maioria dos nós forma poucas conexões (Recuero, 2009b, p.67).

\section{Dinâmicas nas redes sociais virtuais}

Toda e qualquer rede social modifica-se com o tempo, por meio da dinâmica das redes sociais, dependente das interações em uma rede social que podem influenciar sua estrutura. Assim, os processos dinâmicos são emergentes devido ao surgimento de comportamentos coletivos não centralizados, caracterizando-se como um erro da análise de redes sociais não os considerar na compreensão da rede social virtual (Recuero, 2009b). A autora enumera as seguintes dinâmicas: cooperação, competição e conflito; ruptura e agregação; adaptação e auto-organização; e outros comportamentos emergentes.

Acerca da cooperação, Recuero (2009b) diz ser ela o processo formador da rede, podendo ser motivada por interesses individuais, pelo capital social envolvido e por finalidades do grupo, possibilitando a compreensão das ações coletivas dos atores da rede. A competição envolve a luta social, mas exclui a hostilidade ou a agressão, sendo um exemplo a união de atores de uma rede para suplantar os atores de outra rede. Tal competição pode fortalecer a estrutura social ao promover a cooperação e/ou proporcionar bens coletivos de maneira mais rápida, quando se objetiva superar outra rede. $\bigcirc$ conflito pode gerar hostilidade, desgaste e ruptura da estrutura social por ser um antagonismo completo e contribuir para o desequilíbrio. A autora salienta que cooperação, competição e conflitos não são necessariamente distintos e podem estar relacionados.

Para Recuero (2009b), duas das dinâmicas básicas das redes sociais são a agregação, capacidade de agregar mais atores, e a ruptura, possibilidade de que os atores rompam com o grupo, geralmente esperada após conflitos. Desse modo, tais dinâmicas são entendidas como clusterização, que tende a produzir 
nós mais densos que os do restante da rede, principalmente devido à existência de conectores na rede, indivíduos com mais conexões com outros atores do que a média da rede e responsáveis pelo espalhamento de informações.

Acerca da adaptação e auto-organização, Recuero (2009b) observa que as redes sociais estão em constante mudança com o aparecimento de novos padrões estruturais. Como as redes sociais virtuais precisam ter capacidade de adaptação por terem um equilíbrio dinâmico oscilante entre o caos e a ordem, a adaptação é, portanto, a necessidade e a propriedade de manter a rede equilibrada diante das mudanças. Reid citado por, diz que a auto-organização refere-se à criação de regras, direitos e responsabilidades para que todos consigam interagir nas redes sociais virtuais, como, por exemplo, a moderação de fóruns virtuais (Recuero, 2009b, p.89).

Finalizando a discussão das dinâmicas das redes sociais virtuais, Recuero (2009b, p.91) diz que outros comportamentos emergentes podem ocorrer "nascidos da apropriação das ferramentas e das interações entre os atores sociais", pois sempre podem surgir outros comportamentos emergentes "mais específicos e complexos", sendo importante compreender que por meio de tais dinâmicas as redes sociais virtuais não são estáticas e nem independentes do contexto no qual se inserem.

\section{Tipos de redes sociais virtuais}

Compreendendo as redes sociais virtuais como resultantes dos tipos de usos que os atores fazem das ferramentas online, Recuero (2009b) diz haver dois tipos de tais redes: redes emergentes e redes de filiação ou redes associativas. A autora define as redes sociais emergentes como redes expressas por meio da interação entre os atores sociais, nas quais as conexões entre os nós surgem das trocas sociais realizadas pela interação e pela conversação, ambas mediadas pelo computador e criadoras de laços sociais dialógicos, como a rede formada pelos comentários em um blog. Diz-se que essas redes são emergentes por serem constantemente modificadas pelas trocas sociais. Além disso, as redes sociais emergentes são geralmente pequenas, pois as interações mútuas concentram-se em poucos nós devido à necessidade de tempo para interação e de comprometimento com a rede para que as trocas sociais ocor- ram. Por esses motivos, espera-se que tais redes apresentem topologia mais igualitária, distribuída e menos centralizada.

Como redes de afiliação ou redes associativas, a autora compreende as redes derivadas das interações reativas, por serem redes cujas conexões são forjadas por mecanismos de associação ou de filiação em sites que promovem listas de amigos ou de usuários que acompanham as informações divulgadas por outro usuário. Assim, as conexões nesse tipo de rede são mais estáveis e estáticas, por não pressuporem interação mútua, como, por exemplo, no caso em que, adicionando-se alguém ao perfil de um site, o ator adicionado permanecerá na rede independentemente da interação para manter o laço social. Entretanto, essas redes podem reproduzir laços pré-existentes dentro ou fora da Internet.

Sendo assim, essas redes podem ser muito grandes, principalmente se comparadas a redes não virtuais, pois manter os laços (nesse caso, laços fracos) não representa custo para os atores. As redes de afiliação ou redes associativas podem ainda compreender conexões não recíprocas, como no caso dos links unilaterais, em que nem sempre todos os nós participantes pertencem a um mesmo grupo, daí a maior presença de díades do que de tríades. Desse modo, "redes de filiação podem expressar identificação, podem expressar laços sociais, mas seu tamanho grande é típico das possibilidades que a mediação pelo computador proporcionou para a manutenção dos laços sociais" (Recuero, 2009b, p. 100).

\section{Sites voltados à formação de redes sociais virtuais}

A análise de redes sociais possui foco na interação como primado fundamental do estabelecimento das relações entre os atores que formarão as redes sociais, físicas e/ou virtuais, por isso ao analisar-se redes sociais virtuais faz-se obrigatória a existência de um locus onde a interação possa ocorrer para que se possa falar em rede social virtual (Recuero, 2004). Desse modo, tal locus de interação das redes sociais virtuais pode ser, por exemplo, os sites voltados à formação de redes sociais virtuais, ou sites de redes sociais, consequentes da apropriação das ferramentas da CMC por atores sociais e compreendidos como "toda ferramenta que for utilizada de modo a permitir que se expressem 
as redes sociais suportadas por ela [...] espaços utilizados para a expressão das redes sociais na Internet" (Recuero, 2009b, p. 102).

Segundo Recuero (2009a), um site que proporcione conexões entre as pessoas não é uma rede social, é apenas um site. Assim, pode-se compreender que os sites voltados exclusivamente à formação de redes sociais virtuais são, por si só, apenas sites, pois as redes sociais virtuais e as comunidades virtuais são formadas a partir do uso desses sites, que isolados não são redes sociais.

Assim, Boyd e Ellisson (2007, online) entendem os sites de redes sociais como os
sistemas que permitem: i) a construção de uma persona através de um perfil ou página pessoal; ii) a interação através de comentários; e iii) a exposição pública da rede social de cada ator. Os sites de redes sociais seriam uma categoria do grupo de softwares sociais, que seriam softwares com aplicação direta para a comuni- cação mediada por computador [...]. A grande diferença entre sites de redes sociais e outras formas de comunicação mediada pelo compu- tador é o modo como permitem a visibilidade e a articulação das redes sociais

Nesse sentido, Recuero (2009b, p. 103) destaca ainda dois elementos definidos por Boyd e Elisson, em 2007, como característicos dos sites de redes sociais: a apropriação - sistema utilizado para manter redes sociais e dar-lhes sentido - e a estrutura - exposição pública da rede dos atores, que permite a diferenciação entre esse tipo de site e outras ferramentas da CMC:

\begin{abstract}
A apropriação refere-se, portanto, ao uso das ferramentas pelos atores, através de interações que são expressas em um determinado tipo de site de rede social. Já a estrutura tem um duplo aspecto: por um lado, temos a rede social expressa pelos atores em sua 'lista de amigos' ou 'conhecidos' ou 'seguidores'. Por outro, há a rede social que está realmente viva através da troca conversacional dos atores, aquela que a ferramenta auxilia a manter. As conexões decorrentes das listas são normalmente associadas a um link, a uma adição ou a uma filiação preestabelecida pela estrutura do sistema (Recuero, 2009b, p. 103).
\end{abstract}

Recuero (2009b) divide tais sites em sites de redes sociais propriamente ditos (o que neste trabalho chama-se de sites voltados à formação de redes sociais virtuais, por entender-se que tal nomenclatura aponta de modo mais claro a característica básica de tais sites) e sites de redes sociais apropriados. Os sites voltados à formação de redes sociais virtuais são todos aqueles que têm foco em expor e publicar as redes sociais dos atores, sistemas em que há perfis e espaços para publicização das conexões entre os atores, direcionados, principalmente, à amplificação e complexificação dessas redes, sendo a rede social formada por tais sites a consequência do uso dos elementos citados. Como exemplo temos sites como Orkut, Facebook, MySpace, entre tantos outros. Sob outra perspectiva, há ainda os sites de redes sociais apropriados, sistemas que não eram inicialmente voltados para mostrar redes sociais, por não terem espaço para perfis e publicização das conexões, mas que são apropriados pelos atores com esse objetivo, como, por exemplo, weblogs e o Twitter, dentre outros.

\section{Comunidades virtuais}

Nas redes formadas pelos sites de redes sociais podem ocorrer aglomerações dos atores em grupos menores do que o total da rede. Tais aglomerações são compreendidas como comunidades virtuais. Assim, dentro das redes sociais virtuais abrigam-se comunidades virtuais, definidas por Primo (1997) como espaços criados no ciberespaço a partir de um contato repetido entre os indivíduos em um local simbólico delimitado por um tópico de interesse comum.

Recuero $(2001$, p.5) define as comunidades virtuais como agrupamentos humanos que surgem no ciberespaço por meio da comunicação mediada pelas redes de computadores. Desse modo, Rheingold (1996, p. 20), é um dos primeiros autores a utilizar o termo comunidade virtual, entendida por ele como "agregados sociais que surgem na Rede [Internet], quando uma quantidade suficiente de gente leva adiante discussões públicas durante um tempo suficiente, com suficientes sentimentos humanos para formar redes de relações pessoais no espaço cibernético", excluindo de tal conceito de comunidade a necessidade de mesma base territorial, condição obrigatória ao conceito de comunidade tradicionalmente discutido pela sociologia.

Jones (1997, online), elenca alguns pontos fundamentais para a caracterização de uma comunidade virtual: 
(1) um nível mínimo de interatividade, que, para Jones, trata-se da extensão em que essas mensagens em uma sequência têm relação entre si e, especialmente, como as mensagens posteriores têm relação com as anteriores [...] (2) uma variedade de comunicadores, que é condição associada à primeira característica da interatividade, (3) um espaço público comum onde uma porção significativa do grupo de comunicação mediada por computador interativa de uma comunidade ocorre [espaço público: onde está a comunidade; espaço privado: onde ocorrem as trocas de mensagens individuais] [...] (4) Um nível mínimo de associação sustentada, ou ainda, uma quantidade de membros relativamente constante, necessária para o nível razoável da interatividade exposta pela primeira característica.

Assim, Jones (1997, online), diz que a comunidade virtual difere-se do seu suporte tecnológico, uma vez que qualquer serviço online em que usuários têm como único ponto em comum a busca por tal serviço, mas não interagem entre si, não são comunidades virtuais. Nesse sentido, a interatividade é obrigatória para que se tenha uma comunidade virtual, pois essa comunidade, como elemento do ciberespaço, "é existente apenas enquanto as pessoas realizarem trocas e estabelecerem laços sociais" (Recuero, 2001, p. 10).

\section{Capital social em sites de redes sociais virtuais}

Segundo Recuero (2009b), verificar os valores construídos nos sites de redes sociais é um dos elementos mais relevantes da análise, por permitir perceber o capital social construído nesses ambientes. $\bigcirc$ diferencial em relação ao capital social criado nesses sites é que eles são capazes de construir e emergir tipos de capital social que não são facilmente acessíveis em modo off-line, como, por exemplo, a ligação entre centenas de outros atores em uma mesma rede e o acesso a informações em larga escala. Assim, a partir dos tipos de capital social definidos por Bertolini e Bravo (2001), aponta-se os valores mais comuns nos sites de redes sociais e suas apropriações pelos atores: visibilidade, reputação, popularidade,e autoridade.

A visibilidade é um valor porque permite que os nós da rede sejam mais perceptíveis, propiciando que determinado nó amplifique os valores obtidos por meio das conexões que ele estabelece, como suporte social e informação, pois quanto mais conectado está o nó, maior a chance de receber informações circulantes na rede e de obter suporte social quando solicitado. Com isso, a visibilidade decorre da própria presença do ator na rede social e pode possibilitar a criação de outros valores (Recuero, 2009b).

Recuero (2009b, p. 109) cita a reputação como as informações recebidas pelos atores sobre o comportamento dos demais atores e o uso dessas informações para decidirem como se comportarão.

A reputação, portanto, é aqui compreendida
como a percepção construída de alguém pelos
demais atores e, portanto, implica três ele-
mentos: o 'eu' e o 'outro' e a relação entre am-
bos. O conceito de reputação implica direta-
mente o fato de que há informações sobre quem
somos e o que pensamos, que auxiliam os outros
[atores da rede] a construir, por sua vez, suas
impressões sobre nós.

Desse modo, Recuero (2009b) pondera que uma das grandes mudanças no aspecto da reputação no contexto das redes sociais virtuais é que a Internet permite maior controle sobre as impressões deixadas pelos atores. Assim, a reputação é uma percepção qualitativa que pode influenciar na seleção dos atores aos quais determinado ator escolhe associar-se, mas não se refere somente ao número de conexões de um ator em específico. Por isso, Bertolini e Bravo (2001), dizem que a reputação relaciona-se ao capital relacional e cognitivo, por ser uma consequência das conexões estabelecidas pelos atores (capital social relacional) e também por referir-se ao tipo de informação publicada pelo ator (capital social cognitivo).

Acerca da popularidade, Recuero (2009b) diz ser um valor determinado à audiência, também facilitada pelas redes sociais virtuais, seja tal audiência o número de conexões de um ator, as referências dadas a ele, o número de visitas a um perfil, ou o número de comentários em um blog, sendo, portanto, um valor mais relacionado aos laços fracos, por examinar o aspecto quantitativo das conexões e não sua qualidade. Além disso, a popularidade pode ocorrer não por um ator ser considerado positivo, mas por ter alguma reputação (boa ou ruim) que o torne popular, o que liga a popularidade à reputação, mas a dissocia da autoridade. 
Como autoridade entende-se o poder de influência de um nó na rede social, dependente da reputação de um ator, mas não se resumindo a ela, e decorrente do capital social relacional e cognitivo, por incluir a avaliação da autoridade do ator em determinado tema ou assunto. Por isso, "a medida de autoridade é uma medida que só pode ser percebida através dos processos de difusão de informações nas redes sociais e da percepção dos atores dos valores contidos nessas informações (Recuero, 2009b, p. 113 )".

Por fim, Recuero (2009b) esquematiza os capitais sociais nos sites de redes sociais por tipo de capital associado; a visibilidade, portanto, é da ordem do capital social relacional e refere-se ao capital social cognitivo, à popularidade ao capital social relacional e à autoridade ao capital cognitivo.

\section{Informação nos sites de redes sociais virtuais}

Na análise dos sites de redes sociais virtuais, podemos compreender seus atores como usuários das informações compartilhadas nessas redes, além de usuários dos sites que propiciam a formação das citadas redes. Por isso, antes de compreendermos as principais características da difusão de informações nos sites de redes sociais virtuais, faz-se necessário elucidar em qual contexto informacional encontra-se o referido usuário.

Entende-se que o usuário dos sites de redes sociais está inserido no contexto da CMC e do ciberespaço, uma vez que:

o que caracteriza o novo sistema de comunicação, baseado na integração em rede digitalizada de múltiplos modos de comunicação, é sua capacidade de inclusão e abrangência de informação forneceu a infraestrutura para modificações, sem retorno, das relações da informação com seus usuários" (Barreto, 1997, online), pois a "interação mediada via tecnologias de comunicação é um novo meio de construir relações, de identificar simbolicamente grupos, de simular movimentos e atitudes e de transformar a condição da aquisição de conhecimento e de participação" (Almeida, 2003).

As citadas modificações na relação com a informação consistem, basicamente, no fato de a Internet caracterizar-se, simultaneamente, como um repositório da informação a ser recuperada e um canal de comunicação (Freire et al., 2002).

Nesse cenário virtual que propicia ao usuário criar a própria informação, alguns autores falam em Web 2.0:

termo foi proposto entre 2003 e 2004 e designa a segunda geração de produtos e serviços desenvolvidos no contexto da Internet. Pensada inicialmente como uma estratégia de marketing segmentado, a Web 2.0 privilegiou a efetiva colaboração do usuário no processo de organização e personalização da informação e proporcionou, desse modo, a alteração das lógicas de organização e disseminação da informação, agora não mais centralizadas no papel do mediador da informação (Moura, 2009, online).

A busca (recuperação) de informações pelo usuário na Internet pressupõe o auxílio do link - instrumento de construção do conhecimento. Assim, os links permitem organizar o conhecimento e ligar estoques informacionais que tenham afinidade de conteúdo (Freire et al., 2002). Por meio das conexões entre conteúdos que se tornaram relevantes, os links revelam formas sociais de construção do conhecimento. No entanto, a linguagem articulada pelos links não é massiva, é individual, não havendo um centro emissor que dê a palavra final (Nathansohn; Freire, 2005).

Com isso, o ciberespaço é um ambiente informacional de interatividade e interconectividade. Nesse aspecto, a interatividade é compreendida como a possibilidade de acesso a diferentes estoques de informação, às várias formas de interação entre o usuário e às estruturas de informação dos estoques. Ela modifica a relação usuário-tempo-informação e reposiciona os acervos de informação, seu acesso e sua distribuição (Barreto, 1997). 
Por sua vez, a interconectividade, entendida como a possibilidade de o usuário de informação deslocar-se quando desejar de um espaço de informação a outro, altera a relação usuário-espaço-informação. O usuário torna-se o próprio mediador na escolha da informação, determinando suas necessidades e julgando a relevância em tempo real, como se estivesse dentro do sistema de informação (Barreto, 1997).

Assim, a interatividade e a interconectidade caracterizam a informação virtual na realidade virtual como um "novo modelo de acesso, transferência e assimilação da informação que é a realidade virtual. Entendida como uma condição de interação na qual a informação envolve e inclui o receptor através de uma maior condição de participação de sua percepção" (Barreto, 1997).

Consideradas tais premissas básicas ao estudo da informação, do comportamento e da cultura informacional em ambiente virtual, apresentam-se considerações a respeito da difusão de informações nos sites de redes sociais.

\section{Difusão de informações nos sites de redes sociais virtuais}

Segundo Wellman (1992a), a análise de redes sociais busca compreender as relações e as trocas entre os atores da rede, criada e sustentada por essas trocas, que podem ser dos mais variados tipos de recursos. Assim, Haythornthwaite et al. (1995), relatam que os recursos compartilhados pelos atores nas redes sociais virtuais, inseridas no contexto da CMC, são "aqueles que podem ser compartilhados com outros via texto, gráfico, animação, áudio, ou mídia de vídeo, por exemplo, compartilhando informação (notícias ou dados), discutindo assuntos do trabalho, dando suporte emocional, ou fornecendo companheirismo [tradução do autor]".

Para Recuero (2009c), "as redes sociais na Internet alteram de forma expressiva o fluxo de informações na sociedade", pois permitem que todo ator seja um potencial emissor de informações, além de facilitar sua circulação. Assim, a autora afirma que uma das maneiras de entender qualitativamente a troca de informações nos sites de redes sociais é analisar "os valores que são gerados nessas transações informacionais, valores sociais e individuais (capital social)"; o discurso dos atores para entender o sentido construído, sua influência na relação social e as conversações, e verificar quais informações são desconstruídas ou repassadas, entre outras perspectivas de análise.

Com isso, a autora destaca algumas características que acredita que sejam comuns na difusão de informações nos sites de redes sociais. A primeira delas é a influência da estrutura do suporte da rede sobre a difusão de informações, pois, dependendo das suas limitações e das suas possibilidades, a ferramenta pode ter ou não uma característica mais informacional ou social, visto que "a apropriação da ferramenta é que influencia essa difusão [de informações] e como a ferramenta é apropriada também a partir de sua limitação técnica, um influencia o outro" (online).

Também é apontado por Recuero (2009c) o fato de a conectividade da rede influenciar a difusão de informações, porque quanto mais conectada for uma rede, no sentido de maior visibilidade das interações entre os atores, maiores serão as chances de que uma informação seja difundida. Outro apontamento da autora é o de que a qualidade dos laços sociais presentes influencia a difusão de informações, pois alguns tipos de informações parecem propagar-se melhor junto aos amigos, enquanto outras parecem funcionar melhor nos laços fracos, o que pode ser explicado pelo fato de os valores construídos pela rede influenciarem a decisão do ator de passar ou não uma informação adiante, visto que "os atores têm interesses variados e prospectam valores em suas interações.

\section{CONSIDERAÇÕES FINAIS}

Elencados os principais conceitos básicos para a análise das informações circulantes em sites voltados à formação de redes sociais virtuais e dos usos e dos usuários de tais sites, espera-se que a presente revisão teórica possa auxiliar na constituição do arcabouço teórico de pesquisas voltadas a problemáticas que busquem a compreensão de questões relacionadas a tais sites no campo da ciência da informação (CI) e áreas correlatas. Entende-se que tais problemáticas devem estar presentes na $\mathrm{Cl}$, principalmente devido à relevância que atualmente os usuários da Internet têm dado aos sites voltados à formação de redes sociais, não podendo, portanto, a ciência contemporânea, principalmente a da informação, desconsiderar tais usuários e/ou sites, bem como o estudo das informações por eles compartilhadas. 
Assim, espera-se que a presente revisão teórica incentive novos estudos sob a ótica de uma ciência que investigue as práticas informacionais de todos os usuários da informação, inclusive as de um público não especializado, como a maioria dos usuários de sites tão populares como Orkut, Twitter e Facebook.

\section{REFERÊNCIAS}

ALCARÁ, A.R.; DI CHIARA, I.G.; TOMAÉL, M.I. Das redes sociais à inovação. Ciência da Informação, v.34, n.2, p.93-104, 2005. Disponível em: <http://revista.ibict.br/index.php/ciinf/ article/view/642/566>. Acesso em: 1 abr. 2009.

ALMEIDA, C.C. Novas tecnologias e interatividade: além das interações mediadas. DataGramaZero: Revista de Ciência da Informação, v.4, n.4, 2003. Disponível em: <http://www.dgz.org. br/ago03/Art_01.htm > . Acesso em: 16 maio 2009.

ARAÚJO, E.A. Construção social da informação: dinâmicas e contextos. DataGramaZero: Revista de Ciência da Informação, v.2, n.5, 2001. Disponível em: <http://dgz.org.br/out01/ Art_03.htm>. Acesso em: 1 abr. 2009.

ARAÚJO, C.A.A. Estudos de usuários: pluralidade teórica, diversidade de objetos. In: ENCONTRO NACIONAL DE CIÊNCIA DA INFORMAÇÃO, 9., 2008, São Paulo. Anais eletrônicos... Disponível em: <http://www.eci.ufmg.br/bogliolo/downloads/ ARAUJO\%20Enancib\%202008.pdf>. Acesso em: 10 out. 2009.

BARNES, J.A. Social networks. Addison-Wesley Module in Anthropology, v.26, p. 1-29, 1972.

BARRETO, A.A. Mudança estrutural no fluxo do conhecimento: a comunicação eletrônica. Ciência da Informação, v.27, n.2, p. 122127, 1998, Disponível em: <http://revista.ibict.br/index. php/ ciinf/article/view/340/301 > . Acesso em: 10 jan. 2010.

BARRETO, A.A. Perspectivas da ciência da informação. Revista de Biblioteconomia de Brasília, v.21, n.2, p.155-166, 1997. Disponível em: <http://aldoibct.bighost.com.br/PerspectivasCl. pdf>. Acesso em: 16 maio 2009.

BERTOLINI, S.; BRAVO, G. Social capital, a multidimensional concept. 2001. Available from:<http://www.ex.ac.uk/shipss/ politics/research/socialcapital/other/bertolini.pdf > . Cited: 17 Oct. 2004.

BORGATTI, S.P.; EVERETT, M.G. Models of core/periphery structures. Social Networks, v.21, n.4, p.375-395, 1999.

BOURDIEU, P. The forms of capital social. In: UNGLEICHHEITEN, S. Soziale welt, sonderheft 2. Goettingen: Outto Schartz, 1983.

BOYD, D.M.; ELLISON, N.B. Social network sites: definition, history, and scholarship. Journal of Computer-Mediated Communication, v.13, n. 1, 2007. Available from: <http://icmc.indiana.edu/vol13/ issue 1/boyd.ellison.html>. Cited: 22 Jun. 2010.

CAPURRO, R. Epistemology of information science. In: VAKKARI, P.; CRONIN, B. (Ed.) Conceptions of library and information science: historical, empirical and theoretical perspectives. London: Taylor Graham, 1992. p.82-98.

CAPURRO, R. Epistemologia e ciência da informação. In: ENCONTRO NACIONAL DE PESQUISA EM CIÊNCIA DA INFORMAÇÃO: INFORMAÇÃO, CONHECIMENTO E TRANSDISCIPLINARIDADE. 5., 2003. Anais eletrônicos... Disponível em: <http://www.capurro.de/enancib_p.htm>. Acesso em: 10 jun. 2009.

CARDOSO, A.M.P. Retomando possibilidades conceituais: uma contribuição à sistematização do campo da informação social. Revista da Escola de Biblioteconomia da UFMG, v.23, n.2, p.107-114, 1994.

CASTELLS, M. A sociedade em rede. 6. ed. São Paulo: Paz e Terra, 2002.v.1.

COLEMAN, J.S. Social capital and the creation of human capital. American Journal of Sociology, n. 94, (Special Supplement), p.S95-S120, 1988.

COLONOMOS, A. Sociologie des réseaux transnationatiounaux: communautés, entreprises et individus: lien social et système international. Paris: I' Harmattan, 1995.

DAL BELLO, C. Da identidade-perfil ao perfil-sujeito: circunscrição e (re)presentação de personas no Orkut. In: SIMPÓSIO NACIONAL DE CIBERCULTURA, 2., 2008. Anais eletrônicos... Disponível em: <http://www.cencib.org/simposioabciber/PDFs/CC/ Cintia\%20Dal\%20Bello.pdf>. Acesso em: 10 out. 2009.

DAVENPORT, T.H. Ecologia da informação: porque só a tecnologia não basta para o sucesso da era da informação. São Paulo: Futura, 2000.

DIAS, M.M.; PIRES, D. Usos e usuários da informação. São Carlos: Edufscar, 2004

DIAS, L.C. Redes: emergência e organização. In: CASTRO, I.E.; GOMES, P.C.C.; CORRÊA, R.L. (Org.). Geografia: conceitos e temas. 8. ed. Rio de Janeiro: Bertrand Brasil, 2006. cap.5, p.141-162.

DONATH, J.S. Identity and deception in the virtual community. In: KOLLOCK, P.; MARC, S. (Org.). Communities in cyberspace. New York: Routledge, 1999.

DORING, N. Personal home pages on the web: a review of research. Journal of Computer-Mediated Communication, v.3, n.7, 2002. Available from: <http://jcmc.indiana.edu/vol7/issue3/doering. html>. Cited: 20 Dec. 2005.

EFIMOVA, L. What is "beneath your threshold"? Social visibility in persistent conversations. Proceedings HICSSTUTORIAL DAY, 2005. Available from: <https://doc.telin.nl/dscgi/ds.py/ ViewProps/File-47362>. Cited: 5 Oct. 2005.

EMIRBAYER, M.; GOODWIN, J. Network analysis, culture, and the problem of agency. American Journal of Sociology, v.99, n.6, p.1411-1454, 1994

FAZITO, D. A análise de redes sociais (ARS) e a migração: mito e realidade. In: ENCONTRO DA ASSOCIAÇÃO DE ESTUDOS POPULACIONAIS, 13., 2002, Ouro Preto. Disponível em: <http:// www.abep.nepo.unicamp.br/docs/anais/pdf/ 2002 GT MIG STI_Fazito_texto.pdf>. Acesso em: 19 dez. 2003. 
FERREIRA, S.M.S.P. Novos paradigmas e novos usuários da informação. Ciência da Informação, v.25, n.2, p.217-223, 1996. Disponível em: <http://dici.ibict.br/ archive/00000360/01/ Novos_paradigmas_e_novos_usu\%C3\%Al rios.pdf $>$. Acesso em: 10 out. 2009

FIGUEIREDO, N.M. Estudos de usuários. In: FIGUEIREDO, N.M. Estudos de uso e usuários da informação. Brasília: IBICT, 1994.

FLORIANI, V.M. Análise do fluxo informacional como subsídio ao processo de tomada de decisões em um órgão municipal de turismo. 2007. Dissertação (Mestrado em Ciência da Informação) - Universidade Federal de Santa Catarina, Florianópolis, 2009. Disponível em: <http://www.cin.ufsc.br/pgcin/Floriani,\% 20Vivian.pdf>. Acesso em: 10 out. 2009.

FRANCHINELLI, A.C.; MARCON, C.; MOINET, N. A prática da gestão de redes: uma necessidade estratégica da sociedade da informação. 2004. Disponível em: <http://www.comciencia.br/ reportagens/socinfo/info 14.htm>. Acesso em: 11 out. 2004.

FREIRE, I.M. et al. Estudos de usuários: o padrão que une três abordagens. Ciência da Informação, v.31, n.3, p. 103-107, 2002. Disponível em: <http://www.scielo.br/pdf/ ci/v31 n3/al 1v31n3. $\mathrm{pdf}>$. Acesso em: 16 maio 2009.

GARTON, L.; HAYTHORNTHWAITE, C.; WELLMAN, B. Studying online social networks. 1997. Available from: <http://jcmc. indiana.edu/vol3/issue 1/ garton.html\#References $>$. Cited: 1 May. 2009.

GÓMES, D. et al. Centrality and power in social networks: a game theoric approach. Mathematical Social Sciences, v.46, p.27-54, 2003.

GRANOVETTER, M. The strength of weak ties: a network theory revisited. In: MARSDEN, P.V.; LIN, N. (Ed.). Social structure and network analysis. Beverly Hills: Sage, 1982. p.105-130.

GRIFFITH, B.C. (Ed.). Key papers in information science. New York: Knowledge Industry Publication, 1980.

GYARMATI, D.; KYTE, D. Social capital, network formation and the Community Employment Innovation Project. Policy Research Iniciative, v. 6, n.3. Available from: <http://policycyresearch.gc.ca/ page. asp?pagenm $=v 6 n 3$ art 05 $>$. Cited: 4 May 2005

HANNEMAN, R.A. Introduction to social network methods, 2001. Available from: < http://faculty.ucr.edu/ hanneman/SOC157/ NEETEXT.PDF>. Cited: 26 Aug. 2003.

HAYTHORNTHWAITE, C.; WELLMAN, B.; MANTEI, M. Work relationships and media use: a social network analysis. Group Decision and Negotiation, v.4, n.3, 193-21 1, 1995.

JONES, Q. Virtual-Communities, virtual settlements \& cyberarchaelogy: a theoretical outline. Journal of Computer Mediated Communication, v. 3, n. 3, 1997. Available from: <http://jcmc. huji.ac.il/vol3/issue3/jones.html>. Cited: 1 Oct. 1998.

KEBEDE, R. Redes sociais superam o e-mail. Reuters. 2009. Available from: <http://br.hsmglobal.com/notas/43543-redessociais-superam-o-e-mail >. Cited: 2009 Apr. 11.

LALLEMENT, M. História das idéias sociológicas. Petrópolis: Vozes, 2004.

LEMOS, A. A arte da vida: diários pessoais e webcams na internet. In: CONGRESSO BRASILEIRO DE CIÊNCIAS DA COMUNICAÇÃO, 25., 2002, Salvador. Anais eletrônicos... São Paulo: Intercom, 2002. CD-ROM.
LOPES, S.A. A teia invisível: informação e contra informação nas redes de ONGS e movimentos sociais. 1996. Tese (Doutorado em Ciência da Informação) - Instituto Brasileiro de Informação Ciência e Tecnologia, Rio de Janeiro, 1996.

MARTELETO, R.M. Análise de redes sociais: aplicação nos estudos de transferência da informação. Ciência da Informação, v.30, n. 1, 2001. Disponível em: <http://revista.ibict.br/index.php/ ciinf/article/view/226/201 >. Acesso em: 1 abr. 2009.

MARTELETO, R.M.; OLIVEIRA e SILVA, A.B. Redes e capital social: o enfoque da informação para o desenvolvimento local. Ciência da Informação, v.33, n.3, p.41-49, 2004

MARTELETO, R.M.; TOMAÉL, M.I. A metodologia de análise de redes sociais (ARS). In: VALENTIM, M.L.P. (Org.). Métodos qualitativos de pesquisa em ciência da informação. São Paulo: Polis, 2005. Cap. 4, p.81-100.

MOREIRA, W. Os colégios virtuais e a nova configuração da comunicação científica. Ciência da Informação, v. 34, n. 1, 2005. Disponível em: <http://revista.ibict.br/index.php/ciinf/article/ view/635/563>. Acesso em: 1 abr. 2009.

MORIGI, V.J.; SEMENSATTO, S.; BINOTTO, S.F.T. Ciclo e fluxo informacional nas festas comunitárias. Informação \& Sociedade, v.16, n.1 , 2006. Disponível em: <http://www.ies.ufpb.br/ ojs/index.php/ies/article/view/453/1504>. Acesso em: 1 abr. 2009.

MOURA, M.A. Informação e conhecimento em redes virtuais de cooperação científica: necessidades, ferramentas e usos. DataGramaZero: Revista de Ciência da Informação, v. 10, n.2, 2009. Disponível em: <http://www.datagramazero.org.br/abr09/ Art 02.htm>. Acesso em: 16 maio 2009.

NATHANSOHN, B.M.; FREIRE, I.M. Estudos de usuários on line. Revista Digital de Biblioteconomia e Ciência da Informação, v.3, n. 1, p.39-59, 2005. Disponível em: <http://www.sbu.unicamp.br/ seer/ojs/include/getdoc. php?id $=184 \&$ article $=51 \&$ mode $=$ pdf $>$. Acesso em: 1 abr. 2009

OTTE, E.; ROUSSEAU, R. Social network analysis: a powerful strategy, also for information sciences. Journal of Information Science, v.28, n.6, p.441-453, 2002. Available from: <http:// www.h-kretschmer.de/Papers/RousseauSocial\%20Network\%20 Analysis\%20new.pdf>. Cited: 2009 Sept. 23.

PRIMO, A.F.T. A Emergência das comunidades virtuais. In: CONGRESSO BRASILEIRO DE CIÊNCIA DA COMUNICAÇÃO INTERCOM, 20., 1997, Santos. Anais eletrônicos... Disponível em: <http://usr.psico.ufrgs.br/ aprimo/pb/comuni.htm>. Acesso em: 30 ago. 2007.

PRIMO, A. Interação mediada por computador: a comunicação e a educação a distância segundo uma perspectiva sistêmico-relacional. Tese (Doutorado) - Universidade Federal do Rio Grande do Sul, Porto Alegre, 2003

PUTNAM, R.D. Bowling alone: the collapse and revival of American community. New York: Simon \& Schuster, 2000.

RABELLO, O.C. O conteúdo do campo de conhecimento relativo a usuário de biblioteca. In: RABELLO, O.C. Análise do campo de conhecimento relativo a usuário de biblioteca. 1980. Dissertação (Mestrado em Administração de Bibliotecas) - Universidade Federal de Minas Gerais, Belo Horizonte, 1980. 
RECUERO, R.C. Comunidades virtuais: uma abordagem teórica. 2001. In: SEMINÁRIO INTERNACIONAL DE COMUNICAÇÃO, 5., 2001. Anais eletrônicos... Disponível em: <http:// pontomidia.com.br/raquel/teorica.pdf $>$. Acesso em 30 ago. 2007.

RECUERO, R.C. Redes sociais na Internet: considerações iniciais. In: ENCONTRO DOS NÚCLEOS DE PESQUISA DA XXVII INTERCOM, 5., 2004, Porto Alegre. Anais eletrônicos... Disponível em: <http://www.bocc.ubi.pt/pag/recuero-raquel-redes-sociais-na-internet.pdf $>$. Acesso em: 10 out. 2009.

RECUERO, R.C. Redes sociais. In: SPYER, J. (Org.). Para entender a Internet: noções, práticas e desafios da comunicação em rede. 2009a. Disponível em: < http://stoa.usp.br/oerworkshop/ files/1333/7925/Para +entender+a+Internet.pdf > . Acesso em: 19 mar. 2009.

RECUERO, R.C. Redes sociais na Internet. Porto Alegre: Sulina, 2009b. (Coleção Cibercultura). Disponível em: <http://www. redessociais.net/cubocc_redessociais.pdf $>$. Acesso em: 30 ago. 2009.

RECUERO, R.C. Redes sociais na Internet e difusão de informações. 2009c. Disponível em: <http://pontomidia.com.br/raquel/ arquivos/redes sociais na internet e difusao de informacoes. $\mathrm{html}>$. Acesso em: 15 set. 2009.

RECUERO, R.C. Redes Sociais online $x$ redes sociais offline. 2009d. Disponível em: <http://www.pontomidia.com.br/raquel/arquivos/redes sociais online $x$ redes sociais offline. $h t m l>$. Acesso em: 15 set. 2009.

REID, E. Electropolis: communication and communityon internet relay chat. Honoris Thesis: University of Melbourne, 1991.
RHEINGOLD, H. La Comunidad virtual: una sociedad sin fronteras. Barcelona: Gedisa Editorial, 1996. (Colección Limites de La Ciência).

SCHNOOR, T. 90\% dos usuários de Internet no Brasil usam redes sociais diz lbope/NetRatings. Wnews. 2008. Disponível em: $<$ http://wnews.uol.com.br/site/noticias/materia.php?id secao $=4 \&$ id_conteudo $=11008>$. Acesso em: 1 abr. 2009.

SCOTT, J. Social networks analysis: a handbook. 2. ed. London: Sage Publications, 2001.

SIBILIA, P. Os diários íntimos na Internet e a crise da interioridade psicológica do sujeito. 2008. Disponível em: <http://www. antroposmoderno.com/antro-version-imprimir.php?id_articulo $=1147>$. Acesso em: 22 jun. 2010.

SILVA, R.H.A. Sociedade em rede: cultura, globalização e formas colaborativas. 2004. Disponível em: <http://www.bocc.ubi. $\mathrm{pt} / \mathrm{pag} /$ silva-regina-sociedade-em-rede. pdf $>$. Acesso em: 1 abr. 2009.

TOMAÉL, M.I.; ALCARÁ, A.R.; DI CHIARA, I.G. Das redes sociais à inovação. Ciência da Informação, v.34, n.2, p.93-104, 2005. Disponível em: <http://revista.ibict.br/index.php/ciinf/article/ view/642/566 > . Acesso em: 1 out. 2009.

WASSERMAN, S.; FAUST, K. Social network: methods and aplications. Cambridge: Cambridge University Press, 1994. p.3-66.

WELLMAN, B. How to use SAS to study egocentric networks. Cultural Anthropology Methods, v.4, n.2, p.6-12, 1992a

WELLMAN, B. Which types of ties and networks give what kinds of social support? Advances in Group Processes, v.9, p.207-235, 1992b.

WILSON, T.D. Models in information behavior research. Journal of Documentation, v.55, n.3, p.249-70, 1999. 